PHYSICAL REVIEW X 6, 039901 (2016)

\title{
Publisher's Note: Rare-Region-Induced Avoided Quantum Criticality in Disordered Three-Dimensional Dirac and Weyl Semimetals [Phys. Rev. X 6, 021042 (2016)]
}

J. H. Pixley, David A. Huse, and S. Das Sarma

(Received 6 July 2016; published 19 July 2016)

DOI: 10.1103/PhysRevX.6.039901

Subject Areas: Computational Physics,

Condensed Matter Physics

This paper was published online on 29 June 2016 with an incorrect figure. Figure 16(a) has been replaced online as of 13 July 2016.

Published by the American Physical Society under the terms of the Creative Commons Attribution 3.0 License. Further distribution of this work must maintain attribution to the author(s) and the published articles title, journal citation, and DOI. 